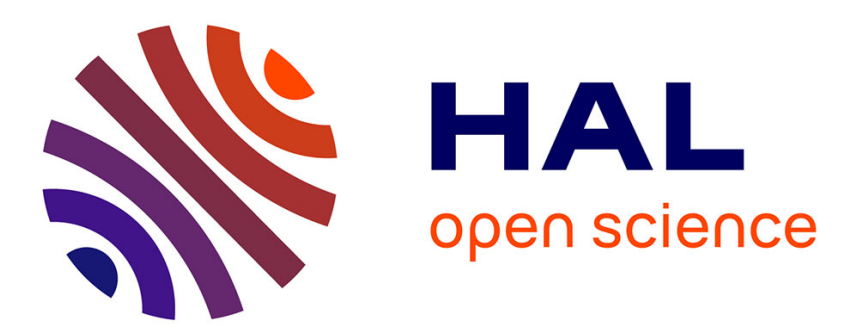

\title{
A social choice approach to primary resource management: The rubber tree case in Africa
}

Moussa Diaby, Hélène Ferrer, Fabrice Valognes

\section{To cite this version:}

Moussa Diaby, Hélène Ferrer, Fabrice Valognes. A social choice approach to primary resource management: The rubber tree case in Africa. Forest Policy and Economics, 2013, 28, pp.8-14. 10.1016/j.forpol.2013.01.002 . halshs-00804065

\section{HAL Id: halshs-00804065 https://shs.hal.science/halshs-00804065}

Submitted on 24 Mar 2013

HAL is a multi-disciplinary open access archive for the deposit and dissemination of scientific research documents, whether they are published or not. The documents may come from teaching and research institutions in France or abroad, or from public or private research centers.
L'archive ouverte pluridisciplinaire HAL, est destinée au dépôt et à la diffusion de documents scientifiques de niveau recherche, publiés ou non, émanant des établissements d'enseignement et de recherche français ou étrangers, des laboratoires publics ou privés. 


\title{
A SOCIAL CHOICE APPROACH TO PRIMARY RESOURCE MANAGEMENT: THE RUBBER TREE CASE IN AFRICA
}

\author{
MOUSSA DIABY, HÉLÈNE FERRER, AND FABRICE VALOGNES
}

\begin{abstract}
We consider in the present paper an original approach to a decision making problem related to the management of a primary resource, namely the rubber tree. By using the social choice theory through the approval voting, we show that it is possible to improve the return of the crop. Hence, by selecting the best varieties to be plant with respect to some environmental constraints, we demonstrate that approval voting can be easily used (opposed to classical operation research methods) by the african rubber tree planters in order to get a plantation at peak performance.
\end{abstract}

\section{INTRODUCTION}

Rubber tree is the original source of two renewable raw materials : natural rubber and rubberwood. Natural rubber is one of the very few industrial raw materials to be produced with a beneficial economic and environmental impact. Global production around 10 million tons a year comes from subtropical area and covers around 10 million ha. The main center of rubber tree crop is located in South East Asia (mainly in Thailand, Indonesia and Malaysia) where the main production takes place with more than $90 \%$ of the global production. Nevertheless Africa (mainly in Ivory Coast, Nigeria, Gabon, Liberia and Cameroon) where the production is only about $6 \%$ has a high comparative advantage in terms of cost of labour forces and of the quality of the latex. This comparative advantage allows Africa to develop significantly this resource since 1970 's $^{1}$ (see Sainte-Beuve et al. 2001). It is also noticeable that the agricultural sector in Africa experienced a rise in poverty which differs according to the crop cultivated. Indeed all the producers, irrespective of the crop, have seen their standard of living falling except for rubber planters who have had a relatively stable situation over the last decade.

Natural rubber production is nowadays realized predominantly by small planters ( $80 \%$ of 10 million ha in the world), supplying regular income during the year. This perennial culture is a long term investment because rubber tapping ${ }^{2}$ begins between 5 and 8 years after planting,

Date: This Version: January 2013

Key words and phrases. Natural Resource Management; Rubber Tree; Social Choice; Group Decision Making.

${ }^{1}$ Having in mind that this production does not compete with the food for locals

${ }^{2}$ The process by which the sap (latex) is collected from a rubber tree. 
and rubber is harvested during a 20 to 30 -year-period. The high yielding varieties will allow small planters to get a good return on investment but also to ensure a long-term stability of plantations. The focus is mainly laid on the determination of the varieties to be grown with respect to the area characteristics.

Since 1964, in order to get agro-economic information on the behavior of varieties, a huge network has been developed ${ }^{3}$. Despite this vast study, remains a problem. There is not enough information about the behavior of the varieties with respect to environmental constraints as for example weather, state of the soil, diseases, etc. According to the different places where rubber tree varieties are located, the production can vary significantly. So the "right plant at the right place" is a sine qua non condition for the production to be efficient. But for a given plot, it is necessary to diversify the varieties in order to reduce the agricultural risks. The question we are raising is the following: How can we choose from the most efficient varieties in order to get the best output in a period of time ranging from 6 to 25 years? ${ }^{4}$

Multicriteria Decision Analysis (MCDA $)^{5}$ in environmental decision making has grown slowly and is now recognized as an integral (see Roy et al. 1992, Hokkanen and Salminen 1997a, 1997b, Martin et al. 2007, Diaby et al. 2010, 2011). . Since the development of agricultural technologies and the diversification of farming have increased in complexity of decision problems, the role of Multicriteria Analysis in farm planning and policy modeling has become important. The MCDA provides to the management of primary resource, a constructive approach for prioritizing decisions which if implemented have a greater chance of success in contributing to sustainable development. Planning and managing the use of primary resources is a complex process which requires taking decisions that inevitably involve several objectives of an economic, environmental and social nature.

Contrary to the multicriteria decision theory, the social choice theory is content with little. The basic task of social choice is to combine individual preferences into a collective choice. When individual utility functions are combined, the aggregation could be interpreted as a social welfare function. Social welfare can be interpreted to include monetary terms such as commodity consumption as well as other values such as collective activities, resource distribution, equity of generations, quality of life etc. (Arrow 1951, Kelly 1988). The social choice situation can be described with four components or parts: 1) Voters or players, 2) Choice alternatives, 3) The information of voters' preferences over the alternatives, 4) An aggregation device (voting model, voting procedure or voting method). It means that voting is also

\footnotetext{
${ }^{3}$ Mainly in Ivory Coast, but also in Nigeria, Cameroon and Gabon.

${ }^{4}$ This is the range for the exploitation of a given plot.

${ }^{5}$ The term MCDA refers to various methods developed to help decision makers in reaching a consensus or compromise.
} 
a reasonable approach for primary resource management when multiple criteria are involved (e.g. Martin et al. 1996, Laukkanen et al. 2004, Kangas et al. 2006).

The approval voting (AV) procedure ${ }^{6}$ was proposed independently by several analysts in the 1970's such as Brams and Fishburn (1978). It is a voting system which is based on dichotomous preferences. Voters divide candidates into two groups, those approved and those not approved, meaning that they can vote for as many candidates as they wish. Each approved candidate receives one vote and the candidate with the most votes wins.

We argue that AV can be also used in multicriteria decision analysis. The decision problem is to select the best alternative among $m$ predefined alternatives. The alternatives are then compared with respect to several criteria that are ranked according to their importance by the decision maker. The next step is to determine which of the alternatives are approved for each criterion. This is done by defining where the threshold between approval and disapproval regarding each criterion lies.

Our study is based upon a panel of 130 varieties. But only the 30 most productive varieties are analysed. Beyond this primary selection several other criteria should be considered before choosing between one and the other variety. Such criteria include rubber tapping, cumulative production during 15 years, wind resistance, disease resistance, physiological resistance, grafting, quality of the hevea.

Our main objective in this paper is to provide to agents that have direct or indirect stake in the rubber tree culture a method that could be used in the development of multi-varietal plantation in order to reduce the risks (diseases, winds), but also to secure some stability in the long term. Varieties are determined according to some scenarios on criteria. We introduce a new threshold namely "the weighted mean of quartiles". We propose a matrix of evaluation with 30 varieties and 11 criteria, to determine a set of the best varieties according to the ecological context.

Fraser and Hauge (1998) presented an application of approval voting, called Multicriteria Approval (MA). Based on thresholds, alternatives are defined to be approved or disapproved with respect to each criterion. If more is preferred to less, an alternative will be approved for the criterion if the criterion value is above the threshold, and if less is preferred to more, it will be approved if the criterion value is below the threshold. With numerical criterion values $c_{j}\left(a_{i}\right)$, the border is the mean criterion value $\bar{c}_{j}=\sum_{i=1}^{m} \frac{c_{j}\left(a_{i}\right)}{m}$ of the $m$ alternatives, with respect to each criterion $j$. This approval border is justified by the fact that according to

\footnotetext{
${ }^{6}$ Beginning in 1987, several scientific and engineering societies adopted AV, including the Mathematical Association of America (MAA) with about 32000 members; the Institute of Operations Research and Management Sciences (INFORMS) with about 12000 members; the Institute of Electrical and Electronics Engineers (IEEE) with about 377000 members and others. The secretary general of the United Nations is also elected by approval voting (Brams and Fishburn 1983). AV has also been used in internal elections by the political parties in some states such as Pennsylvania in 1983 (Nagel 1984).
} 
approval voting theory, the optimal strategy for a voter is to vote for all the candidates that are above average (Kim and Roush 1980). But there are also other ways of determining the limits. A middle rank (when the criterion is evaluated in an ordinal scale) has been used for approval and the midpoint of the range of variation $\bar{c}_{j}=\frac{\max \left(c_{j}\right)+\min \left(c_{j}\right)}{2}$ can be used as well (Laukkanen et al. 2004). We define a new threshold called the weighted mean of the quartiles $\bar{c}_{j}=\frac{\left(c_{j \frac{1}{4}}+2 c_{j \frac{1}{2}}+c_{j \frac{3}{4}}\right)}{4}$ as approval limit. This new threshold is not influenced by aberrant or extreme values (for ex. the mean is sensitive to extreme values) and uses more information than the midpoint value. In this study we use the weighted mean of quartiles, the midpoint and the mean as approval limits to follow the original principles of MA.

The determination of the voting result begins by deciding how many ordinally dominant alternatives exist, using a variation of the ordinal deductive selection system's algorithm.

Alternative $k$ is classified as ordinally dominant if

$$
f(n *)_{k i} \geq 0, \forall n *, 1 \leq n * \leq n, \forall i \neq k
$$

where

$$
f\left(n^{*}\right)_{k i}=\sum_{j=1}^{n^{*}} g_{i j k}
$$

and

$$
g_{i j k}=\left\{\begin{array}{c}
1, \text { if } \quad c_{j}\left(a_{k}\right) \in P \bigcap c_{j}\left(a_{i}\right) \notin P \\
0, \text { if } \quad c_{j}\left(a_{k}\right) \in P \bigcap c_{j}\left(a_{i}\right) \in P \\
0, \text { if } \quad c_{j}\left(a_{k}\right) \notin P \bigcap c_{j}\left(a_{i}\right) \notin P \\
-1, \text { if } \quad c_{j}\left(a_{k}\right) \notin P \bigcap c_{j}\left(a_{i}\right) \in P
\end{array}\right.
$$

where the value of criterion $c_{j}$ in alternative $a_{k}$ is $c_{j}\left(a_{k}\right)$, the value of criterion $c_{j}$ in alternative $a_{i}$ is $c_{j}\left(a_{i}\right)$, the approved set of alternatives is $P$, a comparison between alternatives $a_{i}$ and $a_{k}$ with respect to criterion $c_{j}$ is $g_{i j k}$, and the number of criteria in a comparison is $n^{*}$.

The principle of this formula is described as follows: "Alternative $k$ is classified as ordinally dominant if for every possible value of $n^{*}$, and all other alternatives $i \neq k, f\left(n^{*}\right)_{k i}$ remains greater than or equal to zero. If at anytime, for any $i \neq k$, it becomes negative, alternative $k$ is labelled indeterminate."

The determination of the voting result begins after defining the dichotomous preferences. There are five possible classes of voting result in MA. The voting result is Unanimous if one alternative has been approved with respect to all criteria and no other alternative has been approved with respect to all criteria. Majority result occurs when one alternative has been 
approved with respect to the majority of criteria which have been defined to be the most important. If one alternative has been defined to be superior on the grounds of the order of criteria, and the dichotomous preferences, the result is Ordinally Dominant. The class Unanimous is a subclass of Majority and both of these are subclasses of Ordinally Dominant.

The result is Deadlocked if there are two or more alternatives that are defined to belong to the subsets Unanimous, Majority or Ordinally Dominant. These alternatives are approved with respect to the same criteria. They are also disapproved with respect to the same criteria, and so it is not possible to determine one single superior alternative.

The result is Indeterminate if there is not enough information to determine one superior alternative. There are two or more alternatives between which it is impossible to name the best. This is the case for example if alternative $A$ is approved by more criteria than $B$, but on the the other hand, $B$ is approved by more important criteria than $A$. Thus, more information is needed in addition to the criteria order to make recommendation.

The process is based on the idea that approval with respect to a more important criterion can completely compensate disapproval with respect to a less important criterion. After this process each alternative is labelled as either Ordinally Dominant or Indeterminate (based on pairwise comparisons).

If there is only one single alternative that is Ordinally Dominant next step is to examine if it belongs to subclasses of Ordinally Dominant. If it does not belong to either Unanimous or Majority then it is classified as Ordinally Dominant.

In this study, we apply MA in six scenarios representing the preferences of hevea culture decision makers. We do this in two ways: First, an application of original MA with the mean value as limit, and second a sensitivity analysis of results to change of limit (the midpoint of range of variation and the weighted mean of quartiles).

\section{Methodology}

\subsection{Varieties and criteria selection.}

2.1.1. The varieties. Rubber tree is reproduced (by agronomists) combining different varieties in order to get a homogeneous and high productivity in plantations. Allowing small farmers to get high-performance clones is a priority for some developing countries. Indeed, the rubber tree provides to small farmers a monthly income during about twenty or thirty years old. All trees in plantations of Thailand, India, Guatemala or Ivory Coast practically are clones (Sainte Beuve et al. 2001).

The goal of our study is to select the best varieties among 30 according to our criteria. This allows us to make recommendations to the decision makers in charge of the rubber tree crop. 
Seven main varieties under cultivation, called GT1, PB217, PB235, PB260, PR107, RRIC100 and RRIM600, were studied in the past. These varieties are the best known and constitute a reference sample for other clones study. Eighteen varieties called IRCA were created and selected in Ivory Coast since the 1970?s. Varieties called PB330, PC10, RRIM703, RRIM712 and RRIM802 are varieties created in Malaysia (Clément-Demange et al. 2007).

2.1.2. The criteria. In cooperation with the IFC (French Rubber Institute), the CIRAD (Agriculture Research for Development) works on 130 varieties in large scale in Africa over 40 years. Among these 130 varieties, we have identified the 30 from whom we have some information. The cooperation allowed us to meet both local agronomists from CIRAD and stakeholders who are directly involved in the production of the crops. With the help of the APROMAC (the Ivorian Natural Rubber Association), the main association of the natural rubber actors, survey has been conducted to understand and identify the characteristics and the constraints of our study. Questions were asked regarding the criteria involved. Suggestions from professionals are also solicited which can be useful for improvement of the project.

The main conclusion emanating from the response survey are that all actors have expressed their satisfaction with the performance of the project and agreed that they benefited from it.

After discussion held with the local agronomists from CIRAD and rubber tree crop stakeholders, the following decision criteria were settled upon. Each people was then asked to establish criteria under which the varieties were to be compared. After two meetings, criteria were selected so that they were fully understood and accepted by stakeholders (small farmers for most and industrials). So, a set of 11 criteria was agreed upon collectively based on this inquiries. The choice of varieties is important for technical and economic success of a plantation.

This choice must be done according to production potential and according to the behavior of varieties facing other characteristics (diseases, wind, etc.). These criteria were selected in order to ensure a high return on investment, to maintain the tapped trees' population and to resist diseases. Others criteria tied to rubber output such as physiological resistance, grafting and rubber quality were included in this study.

In a nutshell, we ended up with the following 11 criteria:

(1) Open : growth speed before maturity and precocity of bleeding (in months)

(2) P15 : cumulative production of latex to 15 years (in $\mathrm{kg} / \mathrm{ha}$ )

(3) Wind : wind resistance, breakage of the trunk and uprooting (resistance mark)

(4) TPD : notch dries and necrosis of bark (resistance mark)

(5) Col : tolerance of leaves in colletotrichum (resistance mark)

(6) Cor : tolerance of leaves in corynespora (resistance mark) 
(7) DL : latex diagnosis (mark of physiological robustness of the phloem)

(8) Wood : volume of rough timber (importance mark)

(9) Graf : success in the grafting (success mark)

(10) Oid : tolerance in ö̈dium (resistance mark)

(11) Tec : the technological quality of rubber (quality mark)

Information on the above criteria has been obtained from primary sources such as CIRAD and APROMAC. Additional information is also obtained from secondary sources such as interviews with farmers, discussions with officials, statistics reports etc. Three CIRAD experts from the agriculture department who worked extensively on the above natural rubber problems and have a good knowledge of working of the rubber are requested to settle the criteria. Farmer's involvement is also considered for formulating these criteria as they possess a huge knowledge about the behavior of the rubber tree varieties. Consequently, the implementation of the criteria were carry-out so that both parties (experts and farmers) were unanimous about the criteria involved in the survey.

The rubber production (criteria Open and P15) is the dominant objective, far in front of the production of the rubberwood, in particular in Africa. But the necessity to take into account the financial updating of the results (evolution of the value of receipts and the expenses in time according to the interest rate of the money) makes that the productions of the first years have an economic value much greater than that of the productions of the later years.

Rubber tapping is realized when at least 200 trees (about $40 \%$ of the plantation) have a circumference of the trunk around 50 centimeters to 1 meter above the ground. Hence, the strongest clones start to produce at the age of $4^{1 / 2}$ years old in the favorable ecological conditions of the south of Ivory Coast. The productivity depends on the genetic potential of varieties but also on the ability of the tapper. The number of tapped trees per hectare tends indeed to decrease in time because of the damages due to the wind. Among many clones selected for their high productivity, a small group have a good resistance to breakage. But this concept of resistance remains relative because in some areas, the wind can be extreme. Another problem is related to the emergence of necrosis of the bark, which leads to stopping the flow of latex during tapping. It does not lead to the death of the tree but reduces significantly the performance of plantations. These phenomena of coagulation and necrosis are pooled under the same term of TPD (Tapping Panel Dryness). A biochemical diagnosis realized on the latex (latex diagnosis) allows characterizing the biological performance of the phloem ${ }^{7}$, in connection with the early production capacity, the late production capacity and

\footnotetext{
${ }^{7}$ Tissue in higher plants that conducts synthesized food substances to all parts of the plant.
} 
the sensibility in the TPD. In order to maintain the tapped trees' population criteria Wind, TPD and DL are necessary.

In Africa, two diseases of leaves, namely the colletotrichum and the corynespora are important to consider. The oidium, another leaf disease, has a weak incidence (Oidium affects the young leaves at their first stage of development and leads to important defoliations on the grown-up trees at the time of the refoliation). Mushrooms appearing generally on the leaves of the young trees cause colletotrichum and corynespora. They affect tissues damaged by external causes (the light, the sun, etc.) or bad conditions of vegetations (drought); and lead, if the tree is not treated, to a full destruction of the tree. Various techniques (not presented in this document) are used to treat these diseases. This explain that we are using criteria Col, Cor and Oid.

Other criteria (Tech, Wood, Graf) that are related to rubber output were included in our study. Indeed, some varieties have weak rates of success to the grafting, but this aspect is of little importance in the choice of varieties. Rubber tree provides an excellent timber and contributes to the reforestation. The technological quality of the rubber was a quite few studied element but recent investigations tend to prove the fact that rubber can have interesting technological properties notably in the tyre industry. Before 1965, the criteria used to evaluate the quality were only visual (RSS: ribbed smoked sheets or ADS: air dried sheets). After 1965, physical and chemical criteria were provided (TSR: Technically Specified Rubber). Thus, buyers have a large variety of quality and presentation of natural rubber.

We may add the following remark. A supplementary factor for the choice of clones is due to the fact that the old varieties are much better known than the recent ones. In order to reduce risks, the decision-makers of plantations prefer to use old varieties probably less efficient than some more promising and more recent clones. In fact they try to manage the biggest part of their plantations with old clones but they keep a small part with recent clones in an $R \& D$ vision.

2.2. The scenarios. A scenario is a complete set of rankings chosen according to the ecological context of area culture. In order to choose the different scenarios we asked both our group of local agronomists (three from Ivory Cost) and agronomists from abroad (two from Gabon and one from Nigeria) to order their preferences on the criteria (from the most important to the least one). The representatives were assured of anonymity regarding their answers. So the scenario numbers in the tables do not specify any groups.

The criteria are chosen according to different situations (disease, winds, etc.) that are usually met in the countries (Ivory Coast, Nigeria and Gabon). 
Six scenarios have been established (Table 1) on the basis of agronomists' preferences. Indeed, each scenario corresponds to an agronomist preferences. The scenario S1 is made up of 11 criteria in this preference order (from the best to the worst): P15, Open, Wind, TPD, DL, Col, Cor, Oid, Tech, Wood and Graf. This scenario corresponds to the wish to take into account 11 criteria where early production (P15 and Open) is the most important criteria. In the scenario S2, we keep only 7 criteria (Open, P15, Wind, TPD, DL, Col and Cor) considered as the most important. In the scenario S3, we keep only 5 criteria linked to the production. We eliminate criteria associated with diseases (Colletotrichum and Corynespora). In the scenario $\mathrm{S} 4$, the criterion Wind has much influence (after P15). This criterion has a strong incidence in Ivory Coast. So we have P15, Wind, Open, TPD and DL. In the scenario S5, we introduce the criterion Cor that has more influence than criteria Open and Wind (Corynespora is important in Nigeria). We have 6 criteria in this following decreasing order: P15, Col, Open, Wind, TPD and DL. In the last scenario S6, we make the same as previously but with the criteria Col (Colletotrichum is important in Gabon). So, we have 6 criteria in this decreasing order: P15, Cor, Open, Wind, TPD and DL.

\begin{tabular}{|l|l|l|l|l|l|l|}
\hline $\begin{array}{l}\text { Rank of } \\
\text { criteria }\end{array}$ & S1 & S2 & S3 & S4 & S5 & S6 \\
\hline 1 & P15 & P15 & P15 & P15 & P15 & P15 \\
\hline 2 & Open & Open & Open & Wind & Col & Cor \\
\hline 3 & Wind & Wind & Wind & Open & Open & Open \\
\hline 4 & TPD & TPD & TPD & TPD & Wind & Wind \\
\hline 5 & DL & DL & DL & DL & TPD & TPD \\
\hline 6 & Col & Col & - & - & DL & DL \\
\hline 7 & Cor & Cor & - & - & - & - \\
\hline 8 & Oid & - & - & - & - & - \\
\hline 9 & Tech & - & - & - & - & - \\
\hline 10 & Wood & - & - & - & - & - \\
\hline 11 & Graf & - & - & - & - & - \\
\hline
\end{tabular}

TABLE 1. The scenarios

2.3. The matrix of evaluations. Data are estimates on the behavior of varieties under different criteria. The period of exploitation will be linked to the development of tapping (opening of GT1 in 66 months or $5^{1 / 2}$ years). This criterion is the only whose low values are considered as favorable and are preferred to the high values. The cumulative production over 15 years result from a global analysis of 44 trials with for every year of production (from 6 to 15 years) an adjustment of the annual production of every variety by the ordinary least square statistic. For every variety, the adjusted annual productions are then determined in order to provide a datum of accrued production in 15 years (in $\mathrm{kg}$ ) of dry rubber by hectare. All other 
data are "expert's marks" (all interviewed agronomists are asking to score the behavior of a particular clone according to the different criteria) established between clones from all the known information (table 2).

\begin{tabular}{|c|c|c|c|c|c|c|c|c|c|c|c|}
\hline varieties & $\mathrm{P} 15$ & Open & Wind & TPD & DL & Col & Cor & Oid & Tech & Wood & Graf \\
\hline Units & $\mathrm{kg} / \mathrm{ha}$ & month & $1 \ldots 10$ & $1 \ldots 10$ & $1 \ldots 10$ & $1 \ldots 5$ & $1 \ldots 5$ & $1 \ldots 5$ & $1 \ldots 5$ & $1 \ldots 5$ & $1 \ldots 5$ \\
\hline $\begin{array}{l}\text { Trend of } \\
\text { parameter } \\
\text { variation }\end{array}$ & $\triangle$ & $\nabla$ & $\triangle$ & $\triangle$ & $\triangle$ & $\triangle$ & $\triangle$ & $\triangle$ & $\triangle$ & $\triangle$ & $\triangle$ \\
\hline GT1 & 14516 & 66 & 5 & 5 & 7 & 1 & 4 & 3 & 2 & 2 & 5 \\
\hline PB217 & 16240 & 72 & 9 & 8 & 10 & 1 & 2 & 3 & 1 & 3 & 1 \\
\hline PB235 & 18835 & 54 & 1 & 1 & 1 & 3 & 2 & 1 & 2 & 5 & 3 \\
\hline PB260 & 18702 & 63 & 1 & 1 & 1 & 5 & 1 & 3 & 3 & 4 & 3 \\
\hline PR107 & 8556 & 90 & 10 & 10 & 8 & 2 & 3 & 3 & 5 & 3 & 3 \\
\hline $\mathrm{R} 100$ & 17473 & 57 & 7 & 5 & 4 & 5 & 5 & 3 & 2 & 4 & 1 \\
\hline R600 & 13480 & 72 & 7 & 5 & 3 & 3 & 1 & 5 & 3 & 1 & 3 \\
\hline I18 & 18105 & 66 & 5 & 6 & 2 & 1 & 1 & 3 & 2 & 3 & 3 \\
\hline I19 & 14823 & 62 & 5 & 8 & 8 & 4 & 3 & 3 & 2 & 4 & 3 \\
\hline I41 & 17403 & 64 & 7 & 8 & 8 & 1 & 2 & 2 & 3 & 3 & 1 \\
\hline I101 & 19496 & 64 & 6 & 4 & 4 & 2 & 2 & 3 & 2 & 3 & 3 \\
\hline I109 & 18158 & 63 & 4 & 6 & 6 & 2 & 2 & 3 & 2 & 4 & 3 \\
\hline $\mathrm{I} 145$ & 17864 & 64 & 4 & 3 & 3 & 2 & 2 & 3 & 2 & 2 & 3 \\
\hline I209 & 17380 & 62 & 5 & 4 & 2 & 2 & 2 & 3 & 2 & 2 & 3 \\
\hline I230 & 22477 & 57 & 5 & 5 & 4 & 2 & 1 & 3 & 2 & 4 & 3 \\
\hline I317 & 21448 & 60 & 5 & 2 & 2 & 2 & 2 & 3 & 2 & 4 & 3 \\
\hline I323 & 15739 & 66 & 6 & 3 & 8 & 2 & 2 & 3 & 2 & 3 & 3 \\
\hline I331 & 23467 & 66 & 6 & 5 & 8 & 2 & 2 & 3 & 2 & 3 & 3 \\
\hline $\mathrm{I} 427$ & 18125 & 66 & 6 & 7 & 4 & 2 & 2 & 3 & 2 & 2 & 3 \\
\hline $\mathrm{I} 428$ & 17745 & 64 & 5 & 7 & 6 & 2 & 2 & 3 & 2 & 2 & 3 \\
\hline I523 & 19654 & 62 & 5 & 2 & 3 & 2 & 2 & 3 & 2 & 3 & 3 \\
\hline I631 & 17476 & 66 & 1 & 5 & 4 & 2 & 2 & 3 & 2 & 4 & 3 \\
\hline I733 & 19580 & 62 & 3 & 2 & 4 & 2 & 2 & 2 & 2 & 5 & 3 \\
\hline I804 & 21181 & 64 & 1 & 5 & 3 & 2 & 2 & 3 & 2 & 4 & 3 \\
\hline I840 & 19339 & 64 & 6 & 3 & 3 & 2 & 2 & 3 & 2 & 3 & 3 \\
\hline PB330 & 18300 & 62 & 1 & 3 & 6 & 1 & 2 & 3 & 2 & 5 & 3 \\
\hline PC10 & 16629 & 64 & 6 & 2 & 3 & 2 & 2 & 3 & 2 & 3 & 3 \\
\hline R703 & 19908 & 66 & 2 & 2 & 1 & 1 & 2 & 3 & 2 & 2 & 3 \\
\hline $\mathrm{R} 712$ & 16559 & 66 & 8 & 7 & 4 & 1 & 1 & 3 & 2 & 2 & 3 \\
\hline R802 & 19150 & 64 & 6 & 5 & 8 & 2 & 2 & 3 & 2 & 3 & 3 \\
\hline & & & & & & & & & & & \\
\hline Min & 8556 & 54 & 1 & 1 & 1 & 1 & 1 & 1 & 1 & 1 & 1 \\
\hline $\operatorname{Max}$ & 23467 & 90 & 10 & 10 & 10 & 5 & 5 & 5 & 5 & 5 & 5 \\
\hline
\end{tabular}

TABLE 2. The matrix of evaluations with $\triangle=$ "more is better" and $\nabla=$ "less is better"

\section{The RESUlts}

In the first step, we use the average criterion value as the limit between approved or disapproved varieties. In the second step, we make a sensitivity analysis using other thresholds such as the midpoint of the range of variation and the weighted mean of quartiles.

The limit between approval and disapproval over each criterion is determined by using the mean, the midpoint of the range of variation and the weighted mean of quartiles.

In their study, Laukkanen et al. (2004) used the midpoint of the range of variation as the border of approval and disapproval of each alternative with respect to each criterion. According to them, original MA is quite sensitive to the approval border. Therefore, it is also subject to rank reversal, when new alternatives are introduced or some alternatives are excluded. However, if the approval borders were fixed (independent of the criterion values of 


\begin{tabular}{|l|l|l|l|}
\hline Criteria & $\bar{c}_{j}=\sum_{i=1}^{30} \frac{c_{j}\left(a_{i}\right)}{30}$ & $\bar{c}_{j}=\frac{\max \left(c_{j}\right)+\min \left(c_{j}\right)}{2}$ & $\bar{c}_{j}=\frac{\left(c_{j \frac{1}{4}}+2 c_{j \frac{1}{2}}+c_{j \frac{3}{4}}\right.}{4}$ \\
\hline P15 & 17926,9 & 16011,5 & 18090,5 \\
\hline Open & 64,6 & 72 & 64 \\
\hline Wind & 4,9 & 5,5 & 4,9 \\
\hline TPD & 4,6 & 5,5 & 4,8 \\
\hline DL & 4,6 & 5,5 & 4,6 \\
\hline Col & 2,1 & 3 & 1,9 \\
\hline Cor & 2,1 & 3 & 2 \\
\hline Oid & 2,9 & 3 & 3 \\
\hline Tech & 2,2 & 3 & 2 \\
\hline Wood & 3,2 & 3 & 3 \\
\hline Graf & 2,9 & 3 & 3 \\
\hline
\end{tabular}

TABLE 3. The limit between approval and disapproval for each criterion using the average criterion value, the midpoint of the range of variation and the weighted mean of three quartiles

alternatives considered), rank reversal does not occur even if the number of alternatives were changed.

Using the weighted mean of quartiles, we avoid the main drawback of mean value which is its sensitivity to extremes values. In addition, this new threshold allows us to be close to the reality. This threshold uses more information than the mean or the midpoint of the range of variation (quartiles are a good indicator of dispersal and central tendency).

This threshold is calculated by discarding a certain percentage of the lowest and the highest scores. Hence we compute it by discarding the lower and higher $25 \%$ of the scores. This is a useful estimator because it is less sensitive to outliers than the mean but will still give a reasonable estimate of central tendency and will be less subject to sampling fluctuations than the mean or the midpoint in extremely skewed distributions. We argue that for our purpose the weighted mean of the quartiles is more robust than the rest of the indicators of central tendency. ${ }^{8}$

Using the weighted mean of quartiles as the border decreased the border for criteria "open", "col", "cor" and "tech" and increased the border for criterion "P15" (Table 3).

\footnotetext{
${ }^{8}$ Let's take a fictitious example to emphasize our purpose. Consider the set $\{a, b, c, d, e, f, g, h\}$ of rubber tree varieties with the associated set of performances $\{1,1,2,2,2,4,4,4\}$. In that case if we consider as threshold the mean, the midpoint and the weighted mean of the quartiles we get respectively $2.5,2.5$ and 2.5 . So according to these thresholds, the approved varieties (to be plant) are $f, g$ and $h$. Now consider a ninth variety $i$ with a performance of 17 (i.e. an outlier). If we do again the calculus we see that only variety $i$ is approved by the mean and the midpoint whereas $f, g, h$ and $i$ are approved by the weighted mean of the quartiles. Because we need a polyvariety plantation, is it easily to see that only the weighted mean of the quartiles is the most relevant and the most robust threshold for outliers.
} 
The following tables (tables 4,5 and 6) show approved or disapproved hevea varieties by every criterion using different thresholds ("+" for approved hevea varieties and "-" for disapproved hevea varieties).

\begin{tabular}{|c|c|c|c|c|c|c|c|c|c|c|c|}
\hline varieties & P15 & Open & Wind & TPD & DL & $\mathrm{Col}$ & Cor & Oid & Tech & Wood & Graf \\
\hline GT1 & - & - & + & + & + & - & + & + & - & - & + \\
\hline PB217 & - & - & + & + & + & - & - & + & - & - & - \\
\hline PB235 & + & + & - & - & - & + & - & - & - & + & + \\
\hline PB260 & + & + & - & - & - & + & - & + & + & + & + \\
\hline PR107 & - & - & + & + & + & - & + & + & + & - & + \\
\hline R100 & - & + & + & + & - & + & + & + & - & + & - \\
\hline R600 & - & - & + & + & - & + & - & + & + & - & + \\
\hline $\mathrm{I} 18$ & + & - & + & + & - & - & - & + & - & - & + \\
\hline I19 & - & + & + & + & + & + & + & + & - & + & + \\
\hline I41 & - & + & + & + & + & - & - & - & + & - & - \\
\hline I101 & + & + & + & - & - & - & - & + & - & - & + \\
\hline I109 & + & + & - & + & + & - & - & + & - & + & + \\
\hline $\mathrm{I} 145$ & - & + & - & - & - & - & - & + & - & - & + \\
\hline I209 & - & + & + & - & - & - & - & + & - & - & + \\
\hline $\mathrm{I} 230$ & + & + & + & + & - & - & - & + & - & + & + \\
\hline I317 & + & + & + & - & - & - & - & + & - & + & + \\
\hline I323 & - & - & + & - & + & - & - & + & - & - & + \\
\hline I331 & + & - & + & + & + & - & - & + & - & - & + \\
\hline $\mathrm{I} 427$ & + & - & + & + & - & - & - & + & - & - & + \\
\hline I428 & - & + & + & + & + & - & - & + & - & - & + \\
\hline $\mathrm{I} 523$ & + & + & + & - & - & - & - & + & - & - & + \\
\hline I631 & - & - & - & + & - & - & - & + & - & + & + \\
\hline I733 & + & + & - & - & - & - & - & - & - & + & + \\
\hline I804 & + & + & - & + & - & - & - & + & - & + & + \\
\hline I840 & + & + & + & - & - & - & - & + & - & - & + \\
\hline PB330 & + & + & - & - & + & - & - & + & - & + & + \\
\hline PC10 & - & + & + & - & - & - & - & + & - & - & + \\
\hline R703 & + & - & - & - & - & - & - & + & - & - & + \\
\hline R712 & - & - & + & + & - & - & - & + & - & - & + \\
\hline R802 & + & + & + & + & + & - & - & + & - & - & + \\
\hline
\end{tabular}

TABLE 4. Approvals (+) and disapprovals (-) of the hevea varieties using the mean value.

3.0.1. Step 1. The table 4 leads us to the following results. In the scenario S1, the variety R802 is ordinally dominant because $f(n)_{r 802 i}$ does not take a negative value over all pairwise comparisons. This variety is approved on 5 major criteria (it is not the case for the varieties I101 and I523). The variety R802 is the majority winner. We have the same result in S2. In S3 and S4, the variety R802 is unanimous winner. It is approved by all criteria in these scenarios. The varieties I230, I101, I317, I523 and I840 are quite satisfying because they are approved by the 3 important criteria. In S5, the result is deadlocked. The variety PB235 and 
PB260 are approved by the same criteria and belong to the subset majority (more information is necessary to differentiate these varieties). In S6, the variety R802 is ordinally dominant.

\begin{tabular}{|c|c|c|c|c|c|c|c|c|c|c|c|}
\hline varieties & P15 & Open & Wind & TPD & $\mathrm{DL}$ & $\mathrm{Col}$ & Cor & Oid & Tech & Wood & Graf \\
\hline GT1 & - & + & - & - & + & - & + & + & - & - & + \\
\hline PB217 & + & + & + & + & + & - & - & + & - & + & - \\
\hline PB235 & + & + & - & - & - & + & - & - & - & + & + \\
\hline PB260 & + & + & - & - & - & + & - & + & + & + & + \\
\hline PR107 & - & - & + & + & + & - & + & + & + & + & + \\
\hline R100 & + & + & + & - & - & + & + & + & - & + & - \\
\hline R600 & - & + & + & - & - & + & - & + & + & - & + \\
\hline I18 & + & + & - & + & - & - & - & + & - & + & + \\
\hline I19 & - & + & - & + & + & + & + & + & - & + & + \\
\hline $\mathrm{I} 41$ & + & + & + & + & + & - & - & - & + & + & - \\
\hline I101 & + & + & + & - & - & - & - & + & - & + & + \\
\hline I109 & + & + & - & + & + & - & - & + & - & + & + \\
\hline I145 & + & + & - & - & - & - & - & + & - & - & + \\
\hline I209 & + & + & - & - & - & - & - & + & - & - & + \\
\hline $\mathrm{I} 230$ & + & + & - & - & - & - & - & + & - & + & + \\
\hline I317 & + & + & - & - & - & - & - & + & - & + & + \\
\hline I323 & - & + & + & - & + & - & - & + & - & + & + \\
\hline I331 & + & + & + & - & + & - & - & + & - & + & + \\
\hline I427 & + & + & + & + & - & - & - & + & - & - & + \\
\hline I428 & + & + & - & + & + & - & - & + & - & - & + \\
\hline I523 & + & + & - & - & - & - & - & + & - & + & + \\
\hline I631 & + & + & - & - & - & - & - & + & - & + & + \\
\hline I733 & + & + & - & - & - & - & - & - & - & + & + \\
\hline I804 & + & + & - & - & - & - & - & + & - & + & + \\
\hline $\begin{array}{l}\mathrm{I} 840 \\
\end{array}$ & + & + & + & - & - & - & - & + & - & + & + \\
\hline PB330 & + & + & - & - & + & - & - & + & - & + & + \\
\hline PC10 & + & + & + & - & - & - & - & + & - & + & + \\
\hline R703 & + & + & - & - & - & - & - & + & - & - & + \\
\hline R712 & + & + & + & + & - & - & - & + & - & - & + \\
\hline $\mathrm{R} 802$ & + & + & + & - & + & - & - & + & - & + & + \\
\hline
\end{tabular}

TABLE 5. Approvals (+) and disapprovals (-) of the hevea varieties using the midpoint of the range of variation.

3.0.2. Step 2. By table 5, we can add that the variety PB217 is the variety ordinally dominant in S1. Overall, the other varieties (like I41, I427 and R712) are good enough. When we exclude criteria "oid", "wood", "tech" and "graf" in S2, we have a deadlock between varieties PB217 and I41. In S3 and S4, we have the same result. In S5 and S6, the result is different. The variety ordinally dominant and majority winner is R100.

In table 6 , with the weighted mean of quartiles as border, we have a single variety $\mathrm{R} 802$ that is the unanimous winner in all possible scenarios. 


\begin{tabular}{|c|c|c|c|c|c|c|c|c|c|c|c|}
\hline varieties & P15 & Open & Wind & TPD & $\overline{\mathrm{DL}}$ & $\mathrm{Col}$ & Cor & Oid & Tech & Wood & Graf \\
\hline GT1 & - & - & + & + & + & - & + & + & + & - & + \\
\hline PB217 & - & - & + & + & + & - & + & + & - & + & - \\
\hline PB235 & + & + & - & - & - & + & + & - & + & + & + \\
\hline PB260 & + & + & - & - & - & + & - & + & + & + & + \\
\hline PR107 & - & - & + & + & + & + & + & + & + & + & + \\
\hline R100 & - & + & + & + & - & + & + & + & + & + & - \\
\hline R600 & - & - & + & + & - & + & - & + & + & - & + \\
\hline I18 & + & - & + & + & - & - & - & + & + & + & + \\
\hline I19 & - & + & + & + & + & + & + & + & + & + & + \\
\hline I41 & - & + & + & + & + & - & + & - & + & + & - \\
\hline I101 & + & + & + & - & - & + & + & + & + & + & + \\
\hline I109 & + & - & - & + & + & + & + & + & + & + & + \\
\hline I145 & - & + & - & - & - & + & + & + & + & - & + \\
\hline I209 & - & + & + & - & - & + & + & + & + & - & + \\
\hline I230 & + & + & + & + & - & + & - & + & + & + & + \\
\hline I317 & + & + & + & - & - & + & + & + & + & + & + \\
\hline I323 & - & - & + & - & + & + & + & + & + & + & + \\
\hline I331 & + & - & + & + & + & + & + & + & + & + & + \\
\hline I427 & + & - & + & + & - & + & + & + & + & - & + \\
\hline I 428 & - & + & + & + & + & + & + & + & + & - & + \\
\hline I523 & + & + & + & - & - & + & + & + & + & + & + \\
\hline I631 & - & - & - & + & - & + & + & + & + & + & + \\
\hline I733 & + & + & - & - & - & + & + & - & + & + & + \\
\hline I804 & + & + & - & + & - & + & + & + & + & + & + \\
\hline I840 & + & + & + & - & - & + & + & + & + & + & + \\
\hline PB330 & + & + & - & - & + & - & + & + & + & + & + \\
\hline PC10 & - & + & + & - & - & + & + & + & + & + & + \\
\hline R703 & + & - & - & - & - & - & + & + & + & - & + \\
\hline R712 & - & - & + & + & - & - & - & + & + & - & + \\
\hline R802 & + & + & + & + & + & + & + & + & + & + & + \\
\hline
\end{tabular}

TABLE 6. Approvals $(+)$ and disapprovals $(-)$ of the hevea varieties using weighted mean of quartiles. 


\section{Conclusion}

Ivory Coast remains a devastated country after the troubles of the year 2011 and its economy needs to be rebuilt. Agriculture is one of the main possibility. Indeed since the colonial period, Ivory Coat's economy has been based on the production and export of tropical products. In 2007, Agriculture and forestry account more than one third of the GDP and two third of the exports. So the country's growth has been driven by resource-based export. Rubber can contribute to the growth. The value of rubber exports is more than twice that of coffee, and unlike cocoa and coffee, production was growing very fast until recent years. As the price of natural rubber is determined by the price of synthetic rubber which in turn is driven by the price of crude oil, the future prospects for natural rubber seem very good. In addition, rubber can be harvested fairly consistently throughout the year, providing a stable source of cash income for the local producers since small farms still dominate the sector. As the rubber cultivation is very labor-intensive, it is a good way to employ jobless people and then a good way to reduce poverty. The need to act rapidly and not wasting time in selecting the varieties to be plant, led us to propose to locals a method that is quick to carry out to select the good varieties according to production and environmental constraints.

In this study, a social choice method based on voting theory was applied both to participatory decision support for the rubber tree management in Africa in order to get a set of the best varieties according to 11 criteria and to fight against the deforestation and erosion. It is remarkable that the area of dense forest, which was 12 million ha in 1960, had dwindled to 2.802 million ha by 2007 , representing a loss of over $75 \%$ of the forest in less than half a century. Thus, the development of rubber tree crop in this country allows to reduce human pressure on forests by supplying an excellent timber.

In our study, we generally have ordinally dominant varieties. These varieties such as R802 are either majority winner, or unanimous winner. The results are sensitive to the border approval and the ecological context of culture. Indeed, the use of the weighted mean of quartiles as the border approval is convenient to take into account the uncertainty on the behavior of varieties. The weighted mean of the quartile is almost as resistant to extreme scores as the median and does not wobble as much from sample to sample as does the average in a skewed distribution. This is a good measure of central tendency and it requires more information than the median because it includes the upper and lower quartiles. The weighted mean of the quartiles is then the good compromise.

From the point of view of practical natural resource management, perhaps the greatest advantage of multicriteria approval is in its ability to rank alternative decisions in a multiplecriteria planning situation on the grounds of much less and more rudimentary preference information than in other multicriteria decision making methods. 
The best variety with MA is R802. Other varieties as PB217, I41 and R100 are satisfactory in some scenarios. Two varieties R100 and I19 have a good resistance to leaf diseases. DMs will make their choice according to their preference and the ecological constraints. Then, they will build in this way, a list of 5 to 15 varieties.

Finally, we suggest in Ivory Coast, Nigeria and Gabon the following set of the most efficient Hevea varieties: R802, I523, I840, I101, I317, R100. We can go deeper in the recommendations by giving for each of the following countries the varieties that fulfill their ecological environment:

- Varieties I230 for Ivory Coast.

- Varieties I733, I804, PB235 and PB330 for Nigeria.

- Varieties PB260, I230, I733, I804 and PB235 for Gabon.

We hope that our recommendations will help local producers in recovering high-profit plantations in a resurgent country and will help Ivory Coast rubber industry to be a major driver of rural growth. In this survey, the natural rubber tree crop owners appreciated favouring the rubber tree harvesting system and were interested in providing job opportunities for people living near the crops. This is the first time a voting-procedure-based method is used in group decision support of rubber tree planning. One may wonder what type of threshold fully answers the purpose of practical decision making. We argue that the use of the weighted mean of the quartile is the most relevant. But, as a future research, it could be interesting to study the fact that a rubber tree crop owner or a decision-maker could define a true approval voting limit by himself as a threshold value. 


\section{REFERENCES}

[1] Arrow K.J. 1951. Social choice and individual values. John Wiley and Sons, Inc., New York.

[2] Brams S. J., Fishburn P.C. 1978. Approval voting. American Political Science Review, 72: 831-847.

[3] Brams S. J., Fishburn P.C. 1983. Approval voting. Birkhäuser, boston.

[4] Clément-Demange A., Priyadarshan P.M, Hoa T.T.T and Venkatachalam P. 2007. Hevea rubber breeding and genetics. Plant Breeding Reviews 29(4): 177-283.

[5] Diaby M., Valognes F., Clément-Demange A. 2010. Utilisation d'une méthode multicritere d'aide a la décision pour le choix des clones d'hévéa a planter en Afrique. Biotechnol. Agron. Soc. Environ., 14(2) : 299-309.

[6] Diaby M., Valognes F., Clément-Demange A., Ferrer H. 2011. Multicriteria Decision analysis: a comprehensive decision approach for hevea planting management in Africa. Journal of Multi-Criteria Decision Analysis 18: 187-201.

[7] Fraser N.M. and Hauge J. W. 1998. Multicriteria Approval: Application of Approval Voting Concepts to MCDM Problems. Journal of Multi-Criteria Decision Analysis 7: 263-272.

[8] Hokkanen J., Salminen P. 1997a. Choosing a solid waste management system using multicriteria decision analysis. European journal of operational research 98, 19-36.

[9] Hokkanen J., Salminen P. 1997b. Electre III and IV decision aids in an environmental problem. Journal of Multi-criteria Decision Analysis 6, 215-226.

[10] International Monetary Fund, 2009. Strategy for relaunching development and reducing poverty. Report $09 / 156$.

[11] Kangas A., Laukkanen S., Kangas J. 2006. Social choice theory and its applications in sustainable forest management. Forest Policy and economics 9(1): 77-92.

[12] Kelly J.S. 1988. Social Choice Theory. Springer-Verlag, Berlin.

[13] Kim K.H., Roush R.W. 1980. Introduction to mathematical consensus theory. Marcel Dekker, New York.

[14] Laukkanen S., Palander T. and Kangas J. 2004. Applying voting theory in participatory decision support for sustainable timber harvesting. Canadian Journal Forest Research 34: 1511-1524.

[15] Martin W.E., Shields D.J., Tolwinski B., Kent B. 1996. An application of social choice theory to U.S.D.A. Forest Service decision making. Journal of Policy Modeling 18: 603-621.

[16] Martin C., Ruperd Y. and Legret M. 2007. Urban stormwater drainage management: The development of a multicriteria decision aid approach for best management practices. European journal of operational research Vol.181:338-349.

[17] Nagel J. 1984. A debut for approval voting. PS: Political Science 17:62-65.

[18] Niemi R. G. 1984. Strategic behaviour under approval voting. American Political Science Review 78 : 952-958.

[19] Roy B., Slowinski R., Treichel W. 1992. Multicriteria programming of water supply systems for rural areas. Water Resources bulletin 28(1): 13-31.

[20] Sainte-Beuve J. et al. 2001. Progress on Natural Rubber Prospective Study. Forum IRSG-Bahrain. 
CRem-CNRS 6211, Université de Caen Basse Normandie, 19 rue C. Bloch, F-14032 Caen Cedex E-mail address: diabymoussa@yahoo.fr

CRem-CNRS 6211, Université de Caen Basse Normandie, 19 rue C. Bloch, F-14032 Caen Cedex E-mail address: helene.ferrer@unicaen.fr

CREM-CNRS 6211, Université de Caen Basse Normandie, 19 rue C. Bloch, F-14032 Caen Cedex

E-mail address: fabrice.valognes@unicaen.fr 